\title{
El docente lector como formador de ciudadanos
}

\section{The reading teacher as a trainer of citizens}

Dra. Jennie Brand Barajas es Docente en la Universidad La Salle (México) (jennie.brand@ulsa.mx) (http://orcid.org/0000-0002-8257-2963)

Recibido: 2017-01-30 / Revisado: 2017-03-21 / Aceptado: 2017-04-05 / Publicado: 2017-07-01

\section{Resumen}

El presente es un estudio cualitativo por teorización, que discurre desde el planteamiento del problema de la lectura como recurso básico para la formación de ciudadanos a través de la educación. Se parte de la definición de la capacidad lectora, seguida de la revisión de las características generales del cerebro lector propuestas por Stalisnas Dehaene (2014), así como las revoluciones en los materiales y dispositivos utilizados para la escritura, además de los cambios en las formas de leer, desde las tablillas sumerias hasta las tecnologías digitales. Se plantea el proceso de Educación para el Desarrollo y los rasgos distintivos de la ciudadanía digital, que son: inmediatez en la producción, transmisión y recepción de mensajes; la interactividad entre receptor y productor; la multiautoría, que da nacimiento a "los prosumidores"; la accesibilidad del medio; la libertad de expresión; la democratización del acceso y la apropiación de un espacio público. Todo esto permite contextualizar las nuevas formas de lectura y los nuevos perfiles de lectores, así como generar los espacios virtuales de lectura en donde se forman comunidades de diálogo e intercambio. El estudio llega hasta los docentes y sus biografías lectoras, las cuales definen, en gran medida, su competencia para fomentar la lectura entre sus estu- diantes y su capacidad de movilizarlos hacia la responsabilidad ciudadana a través de la lectura.

Descriptores: Lectura, ciudadanía, libros, docencia, digitalización, responsabilidad.

\begin{abstract}
The present is a qualitative study by theorizing, from the approach of the problem of reading as a basic resource for the formation of citizens through education. It starts from the definition of the reading capacity, followed by the revision of the general characteristics of the reading brain proposed by Stalisnas Dehaene (20|4), as well as the revolutions in the materials and devices used for the writing, besides the changes in the form of reading, from Sumerian tablets to digital technologies. The process of Education for Development and the distinctive features of digital citizenship are presented, which are: immediacy in the production, transmission and reception of messages; interactivity between receiver and producer; the multi-authoritarian, which gives birth to "the prosumers"; the accessibility of the environment; freedom of expression; the democratization of access and the appropriation of a public space. All this allows contextualizing new forms of reading and new profiles of readers, as well as the generation of virtual reading spaces where communi-
\end{abstract}

Forma sugerida de citar: Brand, J. (2017). El docente lector como formador de ciudadanos. Alteridad, 12(2), 165-174. https://doi.org/10.17163/alt.v12n2.2017.03. 
ties of dialogue and exchange are formed. The study reaches the teachers and their reading biographies, which largely define their competence to encourage

\section{Introducción}

El 13 de enero de 2017, siete días antes de dejar la presidencia de los Estados Unidos, Barack Obama concedió una entrevista al periodista del diario New York Times, Michiko Kakutani, para platicar sobre la importancia que han tenido los libros en su vida. El reportaje refiere lo siguiente:

Desde su niñez, a veces solitaria, en la que 'estas palabras portátiles' le hacían compañía, hasta una juventud en la que lo ayudaron a descubrir quién era, qué pensaba sobre el mundo y qué le parecía importante. Y, sobre todo, su efecto a lo largo de ocho años en la Casa Blanca, marcados en parte por una sobrecarga informativa, un partidismo extremo y reacciones con exabruptos. Los libros fueron una fuente de ideas e inspiración, y le dieron una manera de apreciar de nuevo las complejidades y ambigüedades de la condición humana. 'En un momento en el que los eventos suceden tan rápido y se transmite tanta información' dijo que la lectura le presentaba la oportunidad 'de desacelerar y conseguir nuevos puntos de vista', así como tener la habilidad de ponerse 'en los zapatos de otros' (Kakutani, 2017).

Este fragmento sintetiza aspectos centrales del lugar de la lectura en la construcción de la persona y en particular del ciudadano. En primer lugar, la lectura ayuda a poner orden a las ideas, así como alimentarlas para generar otras nuevas o diferentes. Permite contar con una visión caleidoscópica de la condición humana y de las motivaciones que le movilizan. Y finalmente, leer es tener apertura hacia los otros. En este sentido, la lectura es encuentro, con uno mismo, con la comunidad que rodea y con la especie humana en general. Leer nos hace ciudadanos. reading among their students and their ability to mobilize them towards citizen responsibility through reading. Keywords: Reading, nationality, books, teaching profession, digitization, responsibility

El artículo transita desde el acto de leer hasta su importancia en el proceso de ciudadanización. En esta época en la que un espectro amplio de la población discurre por las aulas de la educación formal, el docente se convierte en un promotor de primer orden del gusto por la lectura, así como del organizador de la misma para orientarla hacia la conciencia ciudadana de sus estudiantes.

\section{Fundamentación teórica}

\subsection{La lectura}

La especie humana inventó la escritura hace más de cinco mil años. Desde las primeras letras cuneiformes hasta los códigos digitales, la escritura ha sido el medio de transmisión más importante en la historia de la humanidad. Con ella se desarrolla también la capacidad de lectura, a través de la cual tenemos acceso a los datos de la escritura y a la posibilidad de retener y aprender lo que en ella se plasma. Para Muñoz, Valenzuela, Avendaño y Núñez (2016, p. 54), la lectura se define como:

- Una actividad cognitiva compleja que abarca diversos niveles de procesamiento (Goodman, 2002, citado en Muñoz et al., 2016, p. 54).

- Un sistema de representación y como una práctica académica a partir de un proceso que se inicia con la relación entre la información que proporciona un texto escrito y los conocimientos previos que el lector posee (Martínez, 1999, citado en Muñoz et al., 2016, p. 54).

- Una vinculación con el mundo mediante un acto que está intencionado desde y 
hacia el texto escrito. Es un acto de construcción de significado que implica una situación dialógica entre un texto y un lector, quien debe desplegar para ello una serie de operaciones mentales con la finalidad de alcanzar una interpretación del mismo (Cassany, 2006; Colomer y Camps, 1996; citados en Muñoz et al., 2016, p. 54).

Esto se puede resumir como pensamiento, aprendizaje y vinculación. No hay lugar a dudas sobre la importancia de la lectura en nuestro desarrollo y mejoramiento, sin embargo, estamos tan familiarizados con el acto de leer que dejamos de lado la base que lo hace posible. Como lo plantea en su libro El cerebro lector, Stalisnas Dehaene (2014)

Nuestra habilidad para leer nos pone cara a cara con la singularidad del cerebro humano. ¿Por qué el Homo sapiens es la única especie que se enseña a sí misma activamente? ¿Por qué es único en su capacidad de transmitir una cultura sofisticada? ¿Cómo se relaciona el mundo biológico de las sinapsis y las neuronas con el universo de las invenciones culturales humanas? (p. 16).

En particular sobre la lectura afirma:

Si vamos a reconsiderar la relación entre el cerebro y la cultura, debemos abordar un enigma que llamo la paradoja de la lectura: ¿por qué nuestro cerebro de primates puede leer? ¿Por qué tiene una inclinación a la lectura, aun cuando esta actividad cultural fue inventada sólo hace unos pocos miles de años? Hay buenas razones por las que esta pregunta engañosamente simple merece ser llamada una paradoja. Hemos descubierto que el cerebro alfabetizado contiene mecanismos corticales especializados que están exquisitamente dispuestos para el reconocimiento de las palabras escritas. Es aún más sorprendente que los mismos mecanismos, en todos los humanos, estén sistemáticamente alojados en regiones cerebrales idénticas, como si hubiera un órgano cerebral para la lectura (p. 17).
El autor defiende la hipótesis del "reciclaje neuronal", esto es que algunos sistemas no estaban programados originalmente para funciones que hemos desarrollado como especie, pero tenían el potencial para estar abiertos a los cambios del ambiente. Es el caso del sistema visual, que no estaba diseñado específicamente para la lectura, pero su plasticidad permitió la invención de la escritura como sistema de transmisión de ideas. Agrega Dehaene (2014):

La originalidad de nuestra especie puede venir de una combinación de dos factores: una teoría de la mente (la habilidad para imaginar la mente de los otros) y un espacio de trabajo global consciente (un retén interno donde puede volver a combinarse una infinita variedad de ideas). Ambos mecanismos, inscriptos en nuestros genes, conspiran para hacernos la única especie cultural (p. 23).

Es interesante este abordaje puesto que el origen de la ciudad es la cultura común de un grupo que le permite establecerse en un lugar y organizarlo de acuerdo esos principios comunes. De esos constructos emanan las escrituras y los alfabetos, lo que necesariamente lleva a la lectura. La comunicación surge en el momento de que hay otro. Conforme las sociedades se fueron complejizando, ese "otro" se empezó a distanciar, ya no era solamente a quien se tenía en el entorno, sino alguien a quien se reconocía como similar pero habitando en otro lugar. Así la tradición oral dejó su lugar a la escritura. Así resume Miguel Ángel Herrera (2011), este tránsito:

La lectura fue construida para la ciudad, pues esta última encontraba en la oralidad serias limitaciones para su constitución como tal, la información requerida necesitaba de otro código. Las ciudades en formación acumulaban más gente, necesitaban más espacios, requerían más edificaciones. Así se rompió el vínculo cerrado de lo comunal, el cual se sostenía sin problemas en una comunidad más pequeña y con vínculos de familiaridad; ese vínculo era posible a través de la oralidad, pero en la ciudad en formación la complejidad social puso en crisis a la orali- 
dad: aparecieron nuevas relaciones sociales, las necesidades materiales cambiaron, en el seno de la sociedad se incrustaron extraños con que los que había que socializar, aparecieron otros pueblos, apareció la ciudad. Dentro de un mismo contexto histórico-espacial se encontraron comunidades de contextos culturales algo diferentes, de tal manera que no bastaba sólo con hablar, había que superar un poco al contexto, y la lengua escrita fue constituida para esos fines; fue el sistema que se impuso, era la sociedad del conocimiento la que hacía su aparición, la lengua escrita-ciudadana lo permitió (p. 163).

Esto da cuenta de cómo los instrumentos y las tecnologías surgen en momentos donde resulta necesario reducir la complejidad de la convivencia de los grupos humanos. La escritura permite compartir ideas literales sin la interpretación del emisor oral. También permite contar con un texto preciso que puede ser traducido y compartido. En este sentido afirmaba Jorge Luis Borges (1988):

De los diversos instrumentos del hombre, el más asombroso es, sin duda, el libro. Los demás son extensiones de su cuerpo. El microscopio, el telescopio, son extensiones de su vista; el teléfono es extensión de la voz; luego tenemos el arado y la espada, extensiones de su brazo. Pero el libro es otra cosa: el libro es una extensión de la memoria y de la imaginación (p. 1).

Martyn Lyons (2011), coincide con Borges en el lugar que le otorga al libro, para este autor la facilidad de transporte, la comodidad de su consulta y su capacidad para concentrar una gran cantidad de datos, lo hacen un recurso indispensable.

Sabemos que la escritura nació en rocas y muros de cuevas con representaciones pictóricas. Fue al principios del cuarto milenio a.C. que la burocracia Sumeria inventó la escritura cuneiforme en tablillas de arcilla en las "que los contables registraban los activos con un objeto punzante mediante signos y números" (Lyons, 2011, p. 16). A partir de ahí las escrituras se van haciendo más elaboradas y los materiales para registrarlas hasta llegar al papiro, el pergamino y el papel.

En los siglos II y III de nuestra era se da una gran revolución que lleva al primer formato similar al libro, el códice, que reunía un conjunto de hojas en un solo volumen y fue el origen del actual formato impreso. Muy conocida es la revolución de Gutemberg con su imprenta, pero menos conocida es la llamada "revolución lectora" a finales del siglo XVIII, la cual constituyó "una explosión de literatura recreativa y una expansión de la prensa periódica" (Lyons, 2011, p. 9).

Para el siglo XIX, varios países de Europa logran la alfabetización universal, pero al mismo tiempo, los gobernantes de otras regiones del mundo, particularmente de las colonias, reconocen en la capacidad lectora de sus gobernados, un riesgo para su poder, dado que, a través de la escritura, se transmiten ideas que podrían llevar al cuestionamiento argumentado de la autoridad.

También en el siglo XIX se mejoran los sistemas de producción de los libros, así como los de su distribución y comercialización, esto último gracias a las facilidades de transporte que aportó el tren. Es así que surgen los autores best sellers, entre los que sobresalen: Jane Austen, Alejandro Dumas, Lewis Carroll, Bram Stoker, Oscar Wilde, Víctor Hugo, Julio Verne, Emily Bronte y Fiodor Dostoievsky. Con ellos nacieron los denominados "derechos de autor".

Por otro lado, el libro se convierte en el instrumento principal para educación formal, particularmente en Occidente. Desde entonces, como afirman Caride y Pose (2015) "nos damos a leer el mundo, convencidos de que pocas herramientas son tan poderosas como las que nos proporciona la interacción lectura-escritura para romper barreras entre las personas y los pueblos, los saberes y sus (in)utilidades prácticas" (p. 68).

La lectura nos lleva a la cultura y ésta "es la que nos habilita para el ejercicio de una ciudadanía activa, crítica y democráticamente fructífera (Cerrillo, 2005, citado en Caride y Pose, 2015, p. 68). La lectura genera conciencia crítica que es una condición necesaria para ejercer la ciudada- 
nía. A esto se suma la conciencia de uno mismo, que para Damasio (2010, citado por Caride y Pose, 2015):

Cabe atribuirle la portentosa aptitud de abrirnos a la inspección del mundo, por dentro y a su alrededor: sin ella -como motor incorpóreo que activa a los sujetos para ser testigos de lo que nos pasa- cesamos en el conocimiento de nuestra existencia y de la oportunidad de transcendernos en el pensamiento y en la acción social. Sentir como propias estas opciones es lo que permite asumir la responsabilidad sobre ellas, intelectual y emocionalmente ( $\mathrm{p}$. 69).

Así la lectura cubre la doble función de ampliar nuestra conciencia sobre nosotros mismos, sobre nuestro lugar en la comunidad donde habitamos y sobre los otros. Es una acción para la transformación, cada lectura que hacemos abre nuevos puntos de visión y comprensión del mundo. Desde un lugar fijo, que es el punto de lectura, se despliegan puertas hacia el universo de las letras, y éstas pueden transportarnos tanto a la realidad como a la ficción, movilizando nuestras ideas, emociones y/o impulsos. Pero también, como afirma Damasio, la lectura nos hace responsables, una vez que sabemos algo, ya no se justifica que no lo tengamos presente en nuestro pensar y toma de decisiones.

Afirma Ollero (2005, citado por Caride y Pose, 2015) "la dimensión lectora -no sólo cuánto lee sino qué, cómo, por qué y para qué- de una sociedad es un indicador de la calidad de su educación y de sus valores" (p. 69)

En esta misma línea, Herrera (2011) plantea:

La lectura es una responsabilidad social, de la sociedad en su generalidad, es una responsabilidad de la ciudad. Hoy más que nunca ella es una marca de ciudadanía, por ello la ciudad debe cuidar con esmero lo que leen sus ciudadanos. No se trata de prohibir, sino de orientar las lecturas, la idea es generar sensibilidad lectora, hacerle cierto contrapeso a la sociedad de consumo, la de la imagen comercial, se trata de generar un cúmulo de experiencias y vivencias en torno a lo lector que permitan lecturas más trascendentes (p. 162).

\subsection{Ciudadanía, educación para el desarrollo y ciudadanía digital}

La Red Internacional de Educación para la Ciudadanía y la Transformación Social (s.f.) en su documento Educación para el desarrollo y la ciudadanía global, propone el concepto de Educación para el Desarrollo:

Es un proceso socio-educativo continuado que promueve una ciudadanía global crítica, responsable y comprometida, a nivel personal y colectivo, con la transformación de la realidad local y global para construir un mundo más justo, más equitativo y más respetuoso con la diversidad y con el medio ambiente, en el que todas las personas podamos desarrollarnos libre y satisfactoriamente (sección 3, párr. 2).

Por ciudadanía entienden:

Hace referencia a sujetos de derechos con criterios de análisis crítico y constructivo, personas empoderadas, que entienden la solidaridad como corresponsabilidad [....] La ciudadanía global implica el empoderamiento y la inclusión de todas las personas para una verdadera participación en la promoción de la justicia y lucha contra la pobreza (sección 3, párr. 5).

En esta línea, la educación para el desarrollo tiene las siguientes características:

- Es un proceso porque es un trabajo permanente en el tiempo, a corto, medio y largo plazo, "el proceso educativo para una ciudadanía global supone una praxis de participación y de inclusión en la que las personas puedan experimentar y aprehender en el camino a nivel individual, la transformación de la realidad que tratamos de promover para todos y todas" (sección 3, párr. 3). 
- Las acciones se realizan a través de las modalidades de educación formal, educación no formal e informal.

- La educación para el desarrollo "es un ejercicio crítico de lectura de la realidad que nos lleva al compromiso social con la realidad misma que analizamos. De forma que existe un continuo entre el tipo de personas que queremos formar, los procesos y experiencias que promovemos y las sociedades que ayudamos a construir" (sección 3, párr. 4).

- Es una educación orientada hacia el compromiso y la acción.

- Promueve el poder transformador de lo pequeño, esto se refiere a los cambios profundos en las realidades locales. Esto sin dejar de lado los cambios estructurales que "liberen las economías, las democracias y las culturas para que puedan ser economías, democracias y culturas de vida" (sección 3, párr. 6).

- Enfoque en derechos, lo que implica "creer que todas las personas sin distinción son sujetos de derechos, y que no es posible el desarrollo si no se garantiza el disfrute de los derechos humanos para todas y todos. La consecución del bienestar material y del desarrollo humano integral se ha convertido en un imperativo ético, es el derecho a una justicia global. Y este derecho debe realizarse en condiciones de libertad, dignidad, seguridad económica y acceso a las mismas oportunidades en todos los espacios de participación y desarrollo" (sección 4, párr. 2).

Por tanto, la educación para el desarrollo es un proceso de acciones y compromisos, con un enfoque en los derechos. De esta manera promueve la formación para el ejercicio de la ciudadanía y el bienestar común.

Queda claro el lugar que ha tenido el libro como recurso para la educación de los ciudadanos, sin embargo, en la actualidad existen múltiples vías para acceder a la lectura, la digitalización del mundo permite ahora tener a disposición millones de fuentes disponibles para su lectura. Es en este sentido en que la educación puede orientar las lecturas, frente a la oferta apabullante de internet, se requieren caminos para llegar a contenidos pertinentes y de calidad. Refiere Herrera (2011) que:

Los ciudadanos del siglo XXI deben ser lectores avezados... Los hábitos y las formas de lectura de los ciudadanos se han transformado a partir de la aparición de las TIC, de tal manera que el acceso a material de lectura se ha diversificado y los hábitos y conductas frente a lo que se lee se imitan con facilidad por otros lectores (p. 164).

Estos cambios en los formatos y hábitos de lectura, llevan necesariamente al tema de la ciudadanía digital, a la que Natal, Benítez y Ortiz (2014), con las siguientes características:

1. Inmediatez en la producción, transmisión y recepción de mensajes.

2. La interactividad entre receptor y productor.

3. La multiautoría, que da nacimiento a "los prosumidores", esto es, a los consumidores o usuarios que paralelamente son productores de contenidos en línea.

4. La accesibilidad del medio es quizá el factor con mayor relevancia. El bajo costo y los múltiples dispositivos portátiles por los cuales se puede ingresar a internet con las múltiples tareas que cumplen, lo hacen el medio más accesible y atractivo.

5. La libertad de expresión.

6. La democratización del acceso.

7. La apropiación de un espacio público

\section{Método}

El análisis cualitativo de teorización es una forma de análisis cualitativo orientado a generar inductivamente una teorización respecto a un fenómeno cultural, social o psicológico, permitiendo un esquema que engloba los actores, interacciones y procesos de una saturación social, y así llevar a los fenómenos a una comprensión nueva (Muccielli, 
2001). Se considera que el método cualitativo por teorización es conveniente para la investigación debido a que el objetivo es aproximarse a la comprensión de un fenómeno socio-educativo, produciendo una teoría descriptiva y explicativa.

\section{Análisis. Nueva docencia para nuevos lectores}

La digitalización en general y de las lecturas en particular, llevan a nuevos tipos de alfabetización. Se definen diferentes tipos de le lectores, "híbridos, multi o polialfabetizados... capaces de facilitar la convivencia de las diferentes culturas del siglo XXI, que van desde el lector clásico, habituado al texto impreso, al lector digital, cibernético e hiperconectado" (Caride y Pose, 2015, p. 71)

Lo anterior ha generado la base para la organización de espacios virtuales donde se lee y se escribe sobre la lectura.

En su novedosa y propositiva investigación con adolescentes y jóvenes, Gemma Lluch (2014, pp. 17-19), refiere hallazgos muy interesantes sobre las comunidades virtuales de lectura:

a) Los sujetos las crean, esto es, ya no se generan ni se tutelan desde la escuela o la biblioteca.

b) Construyen sus espacios de comunicación desde plataformas múltiples practicando la trashumancia virtual. Las conversaciones crean un "espacio virtual de comunicación", es decir, un lugar construido por los documentos que escriben sobre un mismo tema pero desde diferentes plataformas.

c) Los lectores crean los espacios, ganando protagonismo y visibilidad. Aunque la editorial o la autora colaboran o intervienen, el usuario es el que produce los contenidos adaptándolos a las normas y a las características de cada red social y de cada plataforma; como consecuencia, el efecto viral de los mensajes es mucho mayor.

d) El hecho lector se transforma en conversación social. En este nuevo contexto, la lectura deja de ser una afición que provoca aislamiento para transformarse en un constructo de conversaciones que permite el intercambio, que les da visibilidad y que posibilita tejer relaciones afectivas.

e) Los jóvenes lectores se convierten en expertos y líderes de opinión.

f) El espacio virtual deviene un lugar de pertenencia y de afecto. Las conversaciones crean espacios donde se forjan lazos de pertenencia a un grupo a través afinidades:

- Son lectores, les gusta la creación y sentirse parte de este universo que les hace sentir especiales.

- Comparten conocimientos sobre los libros que leen, las editoriales que siguen, los autores que les gustan y las campañas de promoción que les enganchan.

- Se ayudan, resuelven las dudas sobre cómo gestionar un blog o sobre libros que buscan.

g) Forman una comunidad competitiva. Aunque son espacios de colaboración, cuando se disputan el acceso a una información privilegiada surge la competencia o rivalidad porque por más que construyan marcos de confianza para compartir información, también compiten por ser los primeros en dar una noticia, leer antes que nadie un libro o tener información privilegiada... Pero también, los chicos utilizan estos espacios para posicionarse, para darse a conocer, para conseguir desde libros gratis hasta un trabajo en la editorial.

Todos estos cambios en las formas de leer, interactuar y compartir de las nuevas generaciones, nos llevan necesariamente a la pregunta de ¿cómo abordan e integran estos cambios los docentes? Granado y Puig (2015), en su artículo La identidad lectora de los maestros en formación como componente de su identidad docente. Un estudio de sus autobiografías como lectores, afirman que: 
"la identidad docente se configura en torno a tres dimensiones: una biográfica, una contextual y otra vinculada a la materia que se enseña o se va a enseñar, en nuestro caso, la lectura" (p. 57). Desde estas tres dimensiones, analizan las trayectorias lectoras de los docentes.

En lo referente a la dimensión biográfica cada docente tiene una trayectoria muy particular como lector. Es importante que cada uno haga un recuento de su autobiografía con la lectura, desde el momento de quién, cómo y en qué contexto aprendió a leer. Si les resultó sencillo o complicado el proceso de aprender a leer cuando eran niños, ¿con qué lecturas se iniciaron?, ¿quiénes leían en su entorno y qué tipo de literatura privilegiaban? ¿Cuáles fueron sus lecturas escolares y si sus docentes fueron lectores y les inspiraron y motivaron a leer? ¿En qué lugares les gustaba leer y con qué estilo de lectura? Tener conciencia de todo esto, les permite reconocer de qué manera viven y transmiten a sus estudiantes el hábito de la leer. Esta labor metacognitiva también facilita la identificación de falencias en los hábitos de lectura y por tanto en la enseñanza de los mismos. Hoy sabemos que nos comunicamos desde diferentes códigos: verbales, no verbales, corporales, actitudinales, afectivos, entre otros. Por tanto, la escena aúlica coloca al docente frente al reto de comunicar con todo lo que es y hace, los estudiantes registran el interés y gusto de sus docentes por cada uno de los temas, de acuerdo a las pautas con que los transmiten.

El contexto es importante, cada escuela tiene programas particulares que dan prioridad a competencias específicas. Podemos decir que hay escuelas lectoras, esto es, instituciones que promueven en sus alumnos el hábito de la lectura a través de diversos medios, desde las asignaturas, hasta ferias del libro y eventos asociados a la lectura y escritura. Mientras más lectora sea una escuela, favorecerá en los docentes lectores, la promoción de la lectura y en aquellos que no lo son, impulsará el gusto por la lectura y su inclusión en la didáctica.
En cuanto a la asignatura que imparten, cabe decir que es una variable importante, hay contenidos que favorecen la promoción de la lectura y otros no. Sin embargo, en aquellas materias donde la lectura no forma parte de sus ejes didácticos prioritarios, los docentes pueden complementar los temas de sus programas con materiales de lectura de apoyo.

La propuesta es clara, como afirma Basanta (2005):

Sólo si somos capaces de abordar con éxito la construcción de una actitud lectora -que, no lo olvidemos, requiere de un esfuerzo inicial-, si generamos una acción mantenida en el tiempo- también la lectura es una causa cuyos frutos se logran a medio y largo plazo-, combinación de diversos y continuados estímulos, enriquecida por la diversidad de las propuestas, animada por la aventura/excitación del descubrimiento y de la atracción, sometedora de la normativa y de la obligación y fruto más del contagio que del dogma, la condición lectora será patrimonio permanente de nuestro alumnado. Que a leer, como a casi todas las cosas importantes de la Vida, también llegamos por imitación (p. 196).

En conjunto esto se denomina identidad lectora (Granado y Puig, 2015), que hace referencia al "modo en que se ven y se cuentan como lectores... en su recorrido vital como lectores" (p. 58).

Es importante que los docentes integren también a sus actividades de aprendizaje los recursos digitales, entre los cuales se encuentran:

- Blogs y wikis para generar plataformas de aprendizaje.

- Infografías como síntesis de lecturas.

- Herramientas de colaboración para la construcción y edición de textos.

- Las páginas web y las fuentes de los recursos con que exponen en clase.

- Trabajos de investigación utilizando herramientas digitales. 


\section{Discusión y conclusiones}

La era digital ha dejado atrás cualquier argumento que implique una limitación acceso a la lectura. La gratuidad de millones de contenidos en internet, hace que la lectura sea hoy más accesible que nunca. Como se mencionó anteriormente, ya no basta con ser ciudadanos, ahora es necesario agregar a la ciudadanía digital, puesto que aún si no lo deseamos, formamos parte de la comunidad global de la red. Podemos estar fuera de todas las redes sociales, no usar correo electrónico, no hacer búsquedas en navegadores digitales, pero aún así, algo de nuestra información se encuentra en la red y tenemos la responsabilidad de dar seguimiento a la misma. Por otro lado, las redes sociales se han convertido en el medio prioritario de transmisión de noticias, por tanto, la opinión pública se genera ahora primero en las redes sociales y luego sale a las calles, donde todos sentimos el impacto de lo que se originó en la nube digital.

Hace apenas unas cuantas décadas, la ciudadanía se construía en el cara a cara, con predominio de la transmisión oral, ahora nos llega vía la lectura. Cuando cobramos conciencia de todo lo que leemos al enviar y recibir mensajes, al seguir redes sociales o leyendo contenidos en internet, descubrimos que quizá somos la generación humana que hasta el momento ha leído más en la historia de la humanidad. De ahí que en la actualidad no baste con enseñar a leer, hay que enseñar a cómo leer y qué hacer con lo leído.

Lo anterior implica la formación de docentes en el desarrollo de competencias digitales, para que sus planeaciones didácticas incluyan el uso de recursos digitales que favorezcan el apego de los estudiantes al hábito de la lectura. La selección de contenidos también es un factor fundamental: debe ser acorde a las edades y características de los alumnos. En este sentido el docente cumple las funciones de compilador, lo cual le requiere una cuidadosa exploración de recursos y contenidos para seleccio- nar aquellos que cumplan con la pertinencia de las asignaturas al tiempo que favorezcan la lectura de textos, su comprensión, su síntesis y su aplicación.

Esto no descarta la lectura de contenidos impresos. Mi experiencia como docente en diferentes niveles educativos, desde educación básica hasta posgrado, me muestra que quien tiene el hábito de portar un libro, lee más y recurre menos a los dispositivos electrónicos como recurso de entretenimiento en tiempos de espera o trayectos. En este sentido un docente tendría que portar siempre un libro consigo y compartir con sus estudiantes su apreciación sobre el contenido revisado, de esta manera es ejemplo, pero también les enseña caminos para organizar la información y aplicarla a contextos específicos.

\section{Referencias bibliográficas}

Basanta, A. (2005). La pasión de leer. Revista de educación, número extraordinario, 189-201. Recuperado de https://goo.gl/NdKkTn

Borges, J.L. (1986). El libro. Bogotá: Taller Gráfico.

Caride, J.A. \& Pose, H. (2015). Leer el mundo hoy o cuando la lectura se convierte en diálogo. Ocnos: Revista de Estudios sobre Lectura, 14, 65-80. Recuperado de https://goo.gl/y8PUjq

Dehaene, S. (2014). El cerebro lector. Argentina: Siglo XXI Editores.

Granado, C. \& Puig, M. (2015). La identidad lectora de los maestros en formación como componente de su identidad docente. Un estudio de sus autobiografías como lectores. Ocnos: Revista de Estudios sobre Lectura, 13, 43-63. Recuperado de https://goo.gl/6EHSsF

Herrera, M.A. (2011). La lectura: una marca de ciudadanía. Zona próxima, 14, 160-167. Recuperado de https://goo.gl/F94w3M

Kakutani, M. (17 de enero de 2017). Los libros q que ayudaron a Barack Obama en la Casa Blanca. The New York Times. Recuperado de https:// goo.gl/YG6L8s

Lluch, G. (2014). Jóvenes y adolescentes hablan de lectura en la red. Ocnos: Revista de 
Estudios sobre Lectura, 11, 7-20. Recuperado de https://goo.gl/WBix9b

Lyons, M. (2011). Libros. Dos mil años de historia ilustrada. España: Lunwerg.

Muccielli, A. (2001). Diccionario de métodos cualitativos en ciencias humanas y sociales. España: Síntesis.

Muñoz, C., Valenzuela, Avendaño, C., \& Núñez, C. (2016). Mejora la motivación por la Lectura Académica: la mirada de estudian- tes motivados. Ocnos: Revista de Estudios sobre Lectura, 15, 52-68. Recuperado de https://goo.gl/619ky8

Natal, A., Benítez, M. y Ortiz, G. (2014). Ciudadanía Digital. México: UAM y Juan Pablos.

Red Internacional de Educación para la Ciudadanía y la Transformación Social (s.f.). Educación para el desarrollo y la ciudadanía global. Recuperado de https://goo.gl/DdrDbd 